\title{
Universiteit
}

Leiden

The Netherlands

\section{Legal Journals: In Pursuit of a More Scientific} Approach

Stolker, C.J.J.M.

\section{Citation}

Stolker, C. J. J. M. (2005). Legal Journals: In Pursuit of a More Scientific Approach. European Journal Of Legal Education, 2(2), 77-94. Retrieved from https://hdl.handle.net/1887/5243

Version: $\quad$ Not Applicable (or Unknown)

License: $\quad$ Leiden University Non-exclusive license

Downloaded from: $\quad$ https://hdl.handle.net/1887/5243

Note: To cite this publication please use the final published version (if applicable). 


\title{
LEGAL JOURNALS: IN PURSUIT OF A MORE SCIENTIFIC APPROACH
}

\author{
C J J M STOLKER ${ }^{1}$, FACULTY OF LAW, LEIDEN UNIVERSITY, \\ THE NETHERLANDS
}

\begin{abstract}
In 1942, the American sociologist of science, Robert Merton, suggested as one of the norms of academic science that universities ought to be places of 'organised scepticism'. Academic law journals should contribute to this mission, since the quality of an academic discipline largely depends on the quality of its publication culture. Informed by the American experiences including the dominant law reviews, and by contrast an international medical journal, this article tries to obtain a better view of the publication culture involving legal scholarship and the possibilities of improving it. The American format of the law review is generally very distant from the form of publication used in most other disciplines and from legal publications in many other parts of the world. One of the major problems of the legal discipline is that non-Americans generally do not publish in American law reviews vice versa. As a consequence, a proper, worldwide academic exchange of ideas is hindered. With the exception of a few journals, the world remains divided. This inhibits progress in legal scholarship. If a 'world format' for a legal article is to be adopted, the European model seems more appropriate than the American one.

This article focuses on the role editorial staffs of journals should play to further progress in our discipline. They have a responsibility towards authors, readers and the academic and professional community as a whole. Changes should be considered at many points with, of course, an open eye for the peculiarities of the legal discipline and for the mistakes made in other academic fields. Furthermore, the poor accessibility of legal literature in Europe must be quickly remedied. In this aspect American legal scholarship is far ahead of its European counterpart. To improve this situation is a task for publishers, but also for national organisations for scientific research. We should think more about the future of our legal journals - the first scientific journal of all was founded by a lawyer.
\end{abstract}

\section{FORM AND CONTENT OF LEGAL WRITING}

In his article 'Goodbye to law reviews', the American law professor Fred Rodell wrote:

1 Dean of the Faculty of Law, Leiden University, Faculty of Law, PO Box 9520, 2300 RA Leiden, The Netherlands. Email: c.j.j.m.stolker@law.leidenuniv.nl. The author would like to thank his colleagues connected with the Strategic Alliance of Research Faculties of Law (SARFaL), and, especially, his British colleague Ewan McKendrick (University of Oxford), and his American colleagues David I Levine (University of California, Hastings College of the Law) and Peter B Kutner (University of Oklahoma) for their comments on earlier drafts. A previous version of this article appeared in the Dutch law journal, 'Wat maakt een juridisch tijdschrift wetenschappelijk?', NJB 2004, p 1409 ff. 
There are two things wrong with almost all legal writing. One is its style. The other is its content.

In the essay, which was especially directed against American law reviews, he declared that he would no longer publish in such journals. ${ }^{2}$

A remark need not be true to be effective. To quote Stendhal: 'Tous les vents sont bons, pourvu qu'ils nous poussent'. Of course, Rodell was being humorous and ironic as well, but he did what legal scholars seldom do: reflect on the nature of their work. This lack of reflection about what is being done typifies legal scholarship, and this is not without some danger. ${ }^{3}$ Legal scholarship is only one discipline among many, and it will soon become aware of this fact. It will notice that the qualitative evaluations of academic research are being increasingly dominated by other disciplines and that the contest for research funds involves all of them. The legal discipline may then hardly receive any notice, as everything concerning nanotechnology and 'genomics' seems to be the order of the day. At the governmental level, the Dutch minister of education, culture and science has set a course that promotes academic collaboration, competition wherever possible and necessary, decreasing direct and increasing indirect governmental funding, emphasis on social relevance, a policy of improving quality, and further internationalisation. Compared to other disciplines, law has fallen behind at almost every point.

Why is this so? In an earlier article (see footnote 3), I adopted the perspective of other disciplines. How do they view us? In brief, my answer was: legal scholarship is considered to have a strong national focus, an individualistic nature and a rather peculiar publishing culture; it is normative, commentative, a discipline lacking an explicitly-defined scholarly method, and one with little interest in empirical research. As a result, it is a remarkable discipline in terms of both form and content. It would seem that Rodell was right. Furthermore, it is difficult to obtain a clear picture of what we do; the study of law is not only one of the behavioural sciences, but also one of the humanities, in which human intentions play a role.

Meanwhile, a change seems to be occurring with regard to the lack of self-reflection in the legal profession. It is for such purposes that the Flemish Inter-university Council in Belgium established the Verbeke commission ${ }^{4}$ and assigned it the task of 'evaluating the quality of academic research in law'. The commission has investigated how universities can improve quality control in legal research, which evaluation criteria are used the most and which evaluation methods and evaluation criteria do really work.

2 Rodell, Fred, 'Goodbye to law reviews' (1936) 23 VA. L. REV. 38. Rodell (1907-80) was affiliated with Yale University. In one of his renowned books, entitled Woe Unto You, Lawyers!, 1939, he explicitly contends with 'legalism'. For a brief description of Rodell's place in American legal culture, see Vinson, Ken, 'Fred Rodell's case against the law' (1996) 24 Florida State University Law Review $107 \mathrm{ff}$.

3 See my article in Dutch, 'Ja, geléérd zijn jullie wel!', Over de status van de rechtswetenschap, NJB 2003, p $766 \mathrm{ff}$, where I indicate that legal studies are entirely absent from the general literature on the philosophy of science.

4 See the report of the Verbeke Commission dated 15 June 2004, Model for the Integral Quality Assessment of Research in Law (www.vlir.be). A similar Dutch commission has reported to the deans of Dutch faculties of law: Oordelen over rechten (October 2005), in Dutch (see www.vnsu.nl). The author had the honour of chairing this commission. 
The responses to my article reveal that there are many of us who also feel a need for something to be done; if not about 'content', then at least involving 'style'. In any event, legal science is not alone in this regard; all academic disciplines and, in particular, the behavioural sciences, run into problems concerning form and content.

Implementing changes based only on defensive arguments would, however, be a mistake. What legal professionals do is, in itself, too important not to reflect on such things from time to time. It is therefore good that, in countries such as Belgium and the Netherlands, a debate has been occurring over the past few years about the various aspects of legal research. In the United States, attention has been focused on 'legal scholarship' for much longer. And to anyone observing developments in other disciplines, it would appear quite likely that the scholarly exercise involving law will become something entirely different in 10 years time.

This article will offer a few remarks about the philosophy of science pertinent to legal scholarship (or 'legal science') (section 2). In order to arrive at a few suggestions involving the future of legal journals, I was inspired by the American situation of which Rodell was so dismissive (section 3) and by a relevant, arbitrarily-chosen medical science periodical: The Journal of Pathology (section 4). Both have rather startling aspects. This will then be followed by my suggestions for possible renewal of our academic law journals (section 5) and a short conclusion (section 6).

\section{A FEW REMARKS ON THE PHILOSOPHY OF SCIENCE}

It is notable that hardly any work done in the philosophy of science is specific to the study of law. Students and young scholars have therefore not acquired any education in this area. The image that legal professionals have of other academic disciplines is strongly based on the natural sciences. They think of Newton and Einstein, of microscopes and pipettes. These belong to the sciences that, or so we often think, lead to statements of truth.

Indeed, science has traditionally been regarded as certain, absolutely reliable knowledge; in fact it has had this status since the beginning of the nineteenth century. Scientific progress consisted of the fact that new certainties were being added to existing ones. And although some people realised that the accuracy of scientific knowledge never could be sufficiently demonstrated, Einstein's theories of relativity were what actually established the notion that science was provisional knowledge. His theories overthrew the traditional ones based on Newtonian science. What had, for some time, been viewed as certain and absolutely reliable knowledge was shown to be the contrary. Why does an apple fall? Newton supposed that two objects separated by some distance could exercise force on each other without the intervention of something else. But he had some deep-running doubts: the notion that matter exercises force and has an influence on other matter without contact 'is so great an absurdity that I believe no man who has in philosophical matters any competent faculty of thinking can ever fall into it'. ${ }^{5}$

5 Newton, I, Correspondence, 1688-94, vol 3, Cambridge: CUP, pp 253, 254. 
This statement would be at home in contemporary thinking about the philosophy of science. Scientific theories constitute provisional knowledge. They therefore ought not to be unassailable or presented as unassailable; this implies that we are ready to refute any posited theory, a notion known as the falsifiability of theory. Anyone who presents a theory as truth is, according to the Austrian philosopher Karl Popper, not practising science. Researchers must be seeking to refute their own theories and not to confirm them. Popper arrived at this insight in his Viennese period, after he became familiar with the theories of Marx, Freud, and Adler, the child psychologist. It struck Popper that their theories could be used to explain so much. For example, whoever clung to Adler's theory found confirming cases everywhere. Popper describes an encounter with Adler:

In 1919, I once told him of a case that did not appear to me to be very Adlerian, but that he had little trouble analysing in terms of his theory of inferiority feelings, although he had not even seen the child. Slightly shocked, I asked him how he could be so certain. 'On account of my thousand-fold experiences', he answered, to which I could not fail to say, 'And with this new case, your experiences now have come to number one thousand and one'. 6

One of Popper's propositions is that every test of a theory is an attempt to falsify it: testability is falsifiability. There are degrees of testability; some theories are more testable, more susceptible to refutation, than others. It is, Popper says, as if they were taking greater risks. This is precisely the case in a context-dependent field of knowledge such as the study of law. ${ }^{7}$ The fact that science takes place in context is, however, not only true of legal science, but also the natural sciences. Ronald Meester, a Dutch professor of mathematics in Amsterdam, has stated:

No, a scientific theory is always produced and to be understood from a certain perspective and in a certain context. There is no question of an objective scientific standard. I cannot state this clearly enough: science makes use of images, analogies, metaphors and intuition. This realisation puts the concept of 'scientific demonstration' in a new light. There turns out to be no objective standard against which we can judge the statement 'scientifically demonstrated. ${ }^{8}$

But what does this mean for scientific practice? How does it affect our method? Is it then the case that 'anything goes'?

In his day, Popper incited some opposition. His idea about the reasonability of science did not, in the eyes of many scientists, agree with the real activities of scientific practice. The greatest and most revolutionary developments in science were just too difficult to explain using the method conceived by the philosopher of science. An important exponent of this thinking was philosopher and artist Paul Feyerabend, who wrote a famous book entitled Against Method:

6 Popper, KR, Conjectures and Refutations: The Growth of Scientific Knowledge, 1963, London: Routledge and Keagan Paul.

7 Sometimes, research even appears to be 'location dependent'. On this subject, see the splendid book by David N Livingstone, Putting Science in its Place - Geographies of Scientific Knowledge, 2003, Chicago: University of Chicago Press, in which the author demonstrates how settings and environments create and influence knowledge.

8 Meester, Ronald, Het pseudoniem van God-een wiskundige over geloof, wetenschap en toeval, 2003, Baarn: Ten Have, p 76 (in Dutch). 
... And my thesis is that anarchism helps to achieve progress in any one of the senses one cares to choose. Even a law-and-order science will succeed only if anarchistic moves are occasionally allowed to take place. ... [T] here is only one principle that can be defended under all circumstances and in all stages of human development. It is the principle: anything goes. ${ }^{9}$

This observation causes us to think, just as the view of Rodell did. Intuition, chance, unexpected inspiration, the failed experiment, the peculiar association - they all have roles to play in scientific research. However, even the 'wrong' theory can be a blessing for scientific progress. Darwin's statement is well-known:

False facts are highly injurious to the progress of science, for they often endure long; but false views, if supported by some evidence, do little harm, for every one takes a salutary pleasure in proving their falseness ... 10

Nevertheless, there is a need to reflect on the method to be used and to be precisely explicit about it in the context-sensitive behavioural and social sciences to which the study of law belongs; especially since the study of law has not traditionally been concerned with the methods being followed. Such self-examination need not place legal science in a straitjacket. To the extent that I can survey and understand the current state of contemporary philosophy of science, I draw the conclusion from it that one ought to be wary about the canonisation of a single theory or a single method. Within certain limits about which there is agreement in the individual discipline, there is room for variety. But this does not lead to 'anything goes'. The study of law is too vulnerable to this extreme.

\section{THE AMERICAN LAW REVIEWS}

Rodell's article led to much discussion about 'legal scholarship' in America. This discussion mainly revolves around the function and importance of law journals. In America, most journals ${ }^{11}$ are the property of law faculties.

As cathedrals to every good-size medieval French town, and as universities to every twentieth century state of the United States, so law reviews are a necessary element of every respectable law school. ${ }^{12}$

Some periodicals are 'faculty-edited' or are published by 'learned societies', 13 but by far the majority of law reviews are produced 'by' students. Since the periodicals were originally established to make a contribution to the education of students and not to

9 Feyerabend, PK, Against Method. Outline of an Anarchistic Theory of Knowledge, 1978, London: Verso, pp 27-28.

10 Darwin, Charles, Descent of Man, 1871, chapt 21.

11 'Journals' or 'reviews'; there is no difference.

12 Noonan Jr, John T, 'Law reviews' (1995) 47 Stanford Law Review 1117.

13 Frequently in the fields of legal economics, the history of law and the sociology of law, but also the American Journal of Comparative Law for example; likely, it is not insignificant that multidisciplinary journals are involved. A few, such as the American Journal of International Law and an estimated 25 others, also practice a form of external peer review. 
legal research, students occupy the editorial positions even now. ${ }^{14}$ It is they who are the gatekeepers of the academic study of law, to the astonishment of other scientific disciplines. Laurence Friedman, the American law professor and sociologist of law, interprets this astonishment:

Law reviews are the primary outlet for legal scholars, and the law review system is unique to legal education. People in other fields are astonished when they learn about it; they can hardly believe their ears. What, students decide which articles are worthy to be published? No peer review? And the students chop the work of their professors to bits? Amazing. And then they check every single footnote against the original source? Completely loco. Can this really be the way it is? Secretly, I share their astonishment; and I think the system is every bit as crazy, in some ways, as they think it is. ${ }^{15}$

Simply stated, such amazement stems from the fact that content decisions are made by non-expert students, who are too often governed by fashion or what they happened to learn in their first year of law school. In regards to form, the articles are much too long; too many of their authors endlessly reproduce the status quo before arriving at something new, and the documents include far too many footnotes. In brief, their format is too school-like.

In most law reviews, even the most obvious of statements is presumed to need adornment; editors (that is students; CS) have demanded support for claims that Plato was an 'influential philosopher' or that 'one of the values of American life is equality'. ${ }^{16}$

And finally, many student editors consider it their task to completely or partially rewrite submitted articles, although this is becoming less true than in the past. It is especially the latter, the rewriting of articles, that annoyed authors. Many legal professors have attempted to change the system, employing either tact or emotion: 'Law professors unite: we have nothing to lose but our chains' ${ }^{17}$

This nonsense must stop. We must turn our professional academic journals into professional academic journals. ${ }^{18}$

But the expectation is that this will not happen. ${ }^{19}$ Students will not surrender their journals; they trivialise the objections and are at most prepared to make small changes. ${ }^{20}$

14 For a history of law reviews, see James W. Harper, Why Student-Run Law Reviews? 82 Minn. L. Rev. 1261 (1998).

15 Friedman, Lawrence M, 'Law reviews and legal scholarship: some comments' (1998) 75 Denver University Law Review 661.

16 Rhode Deborah L, 'Legal scholarship' (2002) 115 Harvard Law Review, p 1335.

17 Taken from a much-cited publication by Lindgren, James, 'An author's manifesto' (1994) 61 University of Chicago Law Review 539. Later, Lindgren wrote a sequel complete with proposals for change: 'Reforming the American Law Review' (1995), 47 Stanford Law Review $1123 \mathrm{ff}$.

18 Lindgren, op cit, 1994, p 527.

19 Friedman, Lawrence, M, 'Law reviews and legal scholarship: some comments' (1998) 75 Denver University Law Review 668: 'The law review system is here to stay, as far as I can tell... They shall continue to mirror what happens in the law schools. It is very unlikely that the law school world will kick its habit of normativity: almost impossible for what I consider real scholarship to become the dominant form in law schools.' This is reiterated by Leo P Martinez in' Babies, BathWater, and Law Reviews' (1995) 47 Stanford Law Review, 1139 ff; he does not expect that having law journals edited by professors would lead to a substantial improvement in quality.

20 'The articles editors, a response' (1994) 61 University of Chicago Law Review 553; in specific, a response to Lindgren (see fn 17). 
What is the view of things on balance? There are a couple of advantages that can be identified in the American system: students perform their work well insofar as they check citations, footnotes, grammatical points ${ }^{21}$ and take a great deal of work off the hands of academic faculty. There are also disadvantages, however. ${ }^{22}$ One of these is that the American format of the law review is very distant from the form of publication used in most other disciplines and from legal publications in other parts of the world. If a 'world format' for a legal article is to be adopted, it should, in my opinion, be the European model, complete with its professional editing, that is more appropriate than the American one. Secondly, one would not expect that non-Americans would ever wish to publish in American law reviews. For example, British authors will likely continue to choose their own periodicals. Peter Birks, the now greatlymissed academic at Oxford, wrote to me two years ago saying: 'For my part, I do not much like publishing in America. The student editors are put under a strange discipline which inflicts amazing pain on them and leaves one's work unrecognisable.' As a consequence, a proper, worldwide academic exchange of ideas is hindered by the law reviews. With the exception of a few journals the world remains divided. This inhibits progress in legal scholarship. ${ }^{23}$

American thinking about 'legal scholarship' can also teach us something, as the competition among the law reviews has caused reflection on the academic study of law to be more developed than it is in Europe. ${ }^{24}$ In this respect, the US has rankings for periodicals ${ }^{25}$ - of course for whatever they may be worth - and therefore experience with the methodology of ranking. ${ }^{26}$

21 See Epstein, Richard A, 'Faculty-edited law journals, symposium on law review editing: the struggle between author and editor over control of the text' (1994) 70 Chicago-Kent Law Review 87.

22 Epstein, ibid, p $88 \mathrm{ff}$.

23 It might be noted, however, that a number of the law journals of law schools in English-speaking countries other than the United States have an operation in between that of the US student-run law reviews and the professionally-edited reviews. Students participate in the reviews and gain experience but academics are more involved in the editorial work or in oversight of the review.

24 For a bibliography up to 1998, see Beazley, Mary Beth and Edwards, Linda H, 'The process and the product: a bibliography of scholarship about legal scholarship' (1998) 49 Mercer Law Review $741 \mathrm{ff}$. Also see the special edition of the Harvard Law Review 115, no. 5 (March 2002).

25 See Shapiro, Fred R, 'The most-cited law reviews' (2000) 29 Journal of Legal Studies 389. At the top of the list of most-cited law reviews are Yale, Harvard, Michigan, Stanford, Columbia, Chicago, Virginia, Pennsylvania, Duke and California. In addition, see Schott Crespi, Gregory, 'Ranking specialized law reviews: a methodological critique' (1999) 26 Florida State University Law Review 835; Korobkin, Russell, 'Ranking journals: some thoughts on theory and methodology' (2002) 26 Florida State University Law Review 851; George, Tracey E and Guthrie, Chris, 'In defense of author prominence: a reply to Crespi and Korobkin' (1999) 26 Florida State University Law Review 877. Moreover, a number of legal journals are included in the Social Sciences Index.

26 The methods of ranking are divergent. Some are based on 'author-prominence' in which an author receives a personal 'ranking', and a subsequent examination is conducted on the number of 'prominent authors' that a law review publishes. The result is an average per law review (see George, Tracey E and Guthrie, Chris, 'An empirical evaluation of specialized law reviews' (1999) 26 Fla.St.U.L.Rev. 813). Another method is derived from a survey of scholars, who indicate on a scale of 1 to 10 which law review that they regard as the most prominent (ScottCrespi, Gregory, 'Ranking international and comparative law journals: a survey of expert opinions' (1997) 31 Int'l Law. 869). Still another method involves the measurement of citation frequency. Use is also made of a 'library usage survey', which examines the frequency with which journals are consulted. For a brief overview of these methods, see George and Guthrie, op. cit. Most social science journals in the US employ 'blind review'. The reviewers don't know the author to avoid being prejudiced by prestige. 
Moreover, the problem of the law reviews seems to have stimulated discussion about electronic publishing. After all, the internet makes a new type of journal possible, and; it offers researchers the chance to create their own forums. It appears to be too soon to draw conclusions about publishing on the internet. Important advantages of the internet are the speed with which research results can be made public, ${ }^{27}$ the availability of research and the possibility of lowering costs. ${ }^{28}$ Quality will be an important key factor. Various models are possible, ranging from peer reviewed electronic publications to 'e-print repositories' ${ }^{29}$ It seems to me that the future of electronic publishing will largely depend on quality and the lifetime of what appears on it.

\section{THE JOURNAL OF PATHOLOGY}

To gain greater insight into the publication culture of legal scholars, I have also consulted a medical science journal. Of course, I could have chosen a history or a language periodical, but on my quest for the future of legal journals, I decided to select a 'long shot'. In Europe, the Journal of Pathology is a leading academic periodical for pathology. Annually, the editorial board, led by a chief editor who is employed on something more than a part-time or honorary basis, receives around 600 articles. Before an article is read, the journal staff review the author's credentials. This occurs by means of a citation analysis: how often are these authors cited and where (what is the impact)? Citations, or so it is assumed, indicate something about the influence that an author, research group or periodical have on scientific debate. Armed with the citation analysis for the author(s), the article is read by one of the editors specialised in the subject and the chief editor. Should they find that the article has sufficient quality, it is then sent to two external readers (peer review). If the externals are positive about the content and consider the article to have sufficient 'impact', the author receives the critical observations of the reviewers as commentary. The permanent journal staff then go over the article: is its methodologically sound, are the references correct (each reference is checked - including its content), and, finally, is proper English used? The rejection rate for this journal is $60 \% .{ }^{30}$ Of further interest is the fact that the reviewers are also evaluated; the journal regularly investigates how the articles given a positive assessment by these reviewers 'are doing' in the citation index. Should the scores turn out to be disappointing, no further use is made of these reviewers' services.

Furthermore, it is important that, in order to promote the independence and therefore the quality of the journal, editorial boards have maximum periods of appointment, and authors are required to indicate any possible conflict of interest along with their articles.

It is not surprising that scientific journals such as the Journal of Pathology are expensive. In the autumn of 2003, this factor led to an initiative given much

27 In some journals in the UK, eg, the delay is over a year.

28 Hibbitts, Bernard J, 'Last writes? Reassessing the law review in the age of cyberspace' (1996) 71 New York University Law Review 615, and many other contributions.

29 An interesting development is the Open Archives Initiative established by P Ginsparg in the United States. It offers scholars the opportunity of soliciting commentary on early drafts of their articles by displaying them on the internet.

30 The absolute top medical journals reject $90 \%$. It is interesting to note that the American Journal of Comparative Law has the same rejection rate of $90 \%$. 
attention: the introduction of PLoS, the Public Library of Science. ${ }^{31}$ PLoS Biology issued its first online journal in October 2003; PLoS Medicine followed in October 2004. Just as with the earlier-mentioned electronic journals, it is also here too early to draw any conclusions.

What does this visit to the doctor's office teach us? What is noteworthy is the quantitative analysis, based on an external peer review that is used to confirm authorial quality; evidently this is perfectly acceptable in the medical world. Another point is the care and thoroughness with which the content of the publication is checked. A third point of note is the easy access to all publications through databases (which subscribers pay for) or, in the near future even, by means of the electronic highway ${ }^{32}$. These last two points - accuracy and accessibility - are what this medical journal has in common with the American law reviews. A fourth issue is the high cost of many scientific periodicals. This problem does not yet affect academic law journals in the same way as it affects, eg, medical journals. ${ }^{33}$ But if legal journals wish to head in the direction of scientific periodicals, there could be some financial consequences for small markets, for example the Netherlands.

\section{OUR LEGAL JOURNALS}

Although I cannot prove it, I expect that the journal will become the most important bearer of scholarly progress in our legal world; it will probably be more important than the book - including the dissertation ${ }^{34}$ - and more important than the thematic collection of essays. This has already happened in the United States. The leading scholars used to be the authors of the major treatises (texts of one volume or more) on the subjects of the law. Now few such treatises are written and the authors do not gain the high standing that the great treatise writers of the past did.

Such a development is visible in many other disciplines (although there are exceptions, especially in the humanities), and the study of law has and will continue to have what are, without doubt, especially influential books. Of all publications, journal articles are probably the ones that have the most lasting influence and that are the easiest to consult over the longer term, especially with the modern search methods. Moreover, periodicals are more consistently subject to scientific testing than books are (dissertations excepted, as they have their own testing procedure ${ }^{35}$ ). And furthermore, the size of a journal article makes it possible to quickly become

31 See www.plos.org.

32 See below text under 'Nedlaw'.

33 Many academic law journals, however, especially those published by commercial publishers, do have high subscription costs. And even if the cost of an individual journal subscription is low, the very large number of law journals published makes subscription cost a great problem if there are to be journals from many countries rather than only from one country or a few countries.

34 In Europe, dissertations (PhDs) are much more important than they are in the US. In the Netherlands alone every year about 90 dissertations, or more, are being published.

35 At the University of Leiden, the size of many $\mathrm{PhD}$ dissertations, particularly in the humanities (including law), is increasingly being viewed as a problem. It is for this reason that a maximum of 100,000 words has been recently imposed. One of the arguments for such a limit concerns the accessibility of the work - and accordingly the ability for readers to evaluate the work's content. 
familiar with its contents, although an exception is certainly provided by the American law review format. Two important comments should be made however. The fact that it is difficult to find books or publications in books electronically does, of course, not justify the elevation of journals. Accessibility should not be used as a substitute for quality. The second comment concerns the real risk that the importance of the journal article will diminish the importance given to scholarly monographs. This is considered to be a real issue in the UK at the moment because the draft criteria for the Research Assessment Exercise (RAE) ${ }^{36}$ give as much weight to one journal article as to a book. Given the importance of having four assessed pieces of work, academics would be better off publishing a book in the form four articles rather than as one book. In other words, there is a real risk that the RAE will dictate the form of future scholarly output.

Reference should be made to the increasing occurrence in US law reviews of the 'symposium' in which numerous authors contribute articles related to the theme of the symposium. Symposium articles, which are much shorter than the usual 'lead article', can be written in a more personal style and possibly with fewer footnotes, and may be less subject to being rewritten by student editors. The 'symposium' is often, but not always, connected to an event at the law school that publishes the law review and it is a way for journals at less prestigious schools to attract prestigious authors (and speakers) for the school. In Europe, too, the symposium is popular; sometimes the papers are published in a journal, more often as a separate book. The place that electronic journals will gain in the periodical repertoire is still uncertain.

This is, nevertheless, no song of praise for the journal. In the sciences, objections are regularly raised against publication in journals: the waiting times are (much) too long, the periodicals are too expensive, the limits placed on the size of publications are too strict; subscribers also pay for publications of no importance to them; editorial boards have become too dependent on their external referees; editors belong to an incrowd, etc.

If it should be true that periodicals will become the prominent bearers of legal scholarly production, this then brings responsibilities as well as the possibilities for new choices for the editors and publishers of journals. I will make a number of suggestions, but will recognise at the same time that far from all these suggestions may be relevant to every journal or to every legal domain. For example, international law already has, in this manner, a strong international publication culture, and several of the journals operating at the international level appear to require hardly any incentives. Nonetheless:

\section{Attention of editorial boards to their tasks and responsibilities}

The editorial staffs of journals are important for progress in any academic discipline. They consequently have a responsibility towards authors, readers and the community

36 The RAE provides quality ratings for research across all disciplines. 
as a whole. And not only concerning the community of today: 'Journals form the scientific archive: they are the official public records of scientific achievement. ${ }^{37}$

Editorial boards are required to make an adequate selection from the offered contributions, a selection that connects with the audience at whom the journal is directed. Editors test the qualities of the submissions and are concerned with 'scholarly integrity'. ${ }^{38}$ The testing of quality is extremely important. In many branches of academia, there is an increasing pressure to publish. The quantitative requirements, which are being imposed virtually everywhere, can lead to research results being sprinkled across several publications: researchers are in search of the 'smallest publishable unit'. New forms of funding research give researchers a feeling of unease and competition: speed before quality. The resulting pressure has distressing features. Science is certainly polemical, writes the famous Dutch historian Huizinga, but it is an adverse sign

... when, in an area of knowledge, the desire to make a discovery ahead of others or to refute an argument, moves strongly to the forefront. The true pursuit of knowledge about reality through research places little value on the victory over an opponent. ${ }^{39}$

Journal editors bear an important responsibility to restore and then maintain the calm.

Finally, editorial boards are responsible for informing their readers about, what is for them, important developments in other areas, along with developments outside national boundaries. I will provide more detail on this point later. Selecting, testing and informing - those are, in my view, the key editorial tasks. ${ }^{40}$

\section{Focus of academic publications}

Journal editors must think more about their 'focus'. The Flemish Inter-university Council in Belgium (see above) is already forcing legal journals to reveal their colours. Periodicals can be roughly divided into journals that contribute to the progress of research ('increasing the body of knowledge'), journals that are directed at explanations of practice ('disseminating the body of knowledge'), and 'house journals' ('promotional literature'). ${ }^{41}$ The last category, which is for that matter not unimportant, will not be given any consideration here.

37 Houghton, Bernard, Scientific Periodicals - Their Historical Development, Characteristics and Control, 1975, London: Clive Bingly, p 43. See also the more recent study by Gross, Alan G, Harmon, Joseph E and Reidy, Michael, Communicating Science - The scientific article from the 17th Century to the Present, 2002, Oxford: OUP; their analysis focuses on the changes over time in prose style, presentation of text and graphics, and ways of arguing.

38 See the Netherlands Code of Conduct for Scientific Practice - Principles of good scientific teaching and research, by the Association of Universities in the Netherlands, Amsterdam, 25 October 2004. See also an American counterpart: 'On Being a Scientist: Responsible Conduct in Research', The National Academy of Sciences / National Academy of Engineering / Institute of medicine, Washington, 1995. Furthermore, see the book by Marcel C. LaFollette, Stealing into print, Fraud, Plagiarism, and Misconduct in Scientific Publishing, 1992, Berkeley: University of California Press, especially p $133 \mathrm{ff}$. Opinions concerning the possible independent role that an editorial board has in testing the principles of scientific integrity have proven to be divided, along with the places in which they are found.

39 Huizinga, Johan, Homo Ludens, 1951, third printing, Haarlem, p 209 (original in Dutch).

40 See the exhaustive information in LaFollette's book, op cit, 1992, chapt 5 ('Decision Making Editors and Referees'), see fn 38.

41 For a more or less comparable categorisation, see Houghton, op cit, 1975, p 32 ff, see fn 37. 
The readership of nearly all legal journals - both academic and professional consists of academics and practitioners. This is a characteristic feature of academic legal research. A development such as the one that scientific journals have undergone is not one that law journals should be expected to follow. Originally, scientific periodicals were frequently directed at a mixed public. At its origin in 1869, Nature had as its 'mission' the aim of being: 'popular in part, but also sound, and part devoted to scientific discovery'. ${ }^{42}$ Only after the First World War did it develop into a purely scientific journal. For progress in legal scholarship, it would be disastrous if most legal journals should choose to target an exclusively academic readership. Our scientific journals should be popular in part, but also sound, and in part devoted to scientific progress. Their audience consists of both academics and practitioners (attorneys, judges, corporate lawyers) Posner claims not to know of any legal academic article that cannot also be understood by practising lawyers. ${ }^{43}$ This is definitely one of the strengths of legal scholarship.

The readership will turn out to be mixed. But if separation is not always possible, distinctions can certainly be made. When journals are to choose a focus, a certain distinction exists between journals that are more strongly directed towards scholarly progress and journals that are intended to provide explanations for practising lawyers (professional groups). Periodicals must not always wish to do everything. ${ }^{44}$ Annotations and short commentaries appear to receive a relatively great deal of space. For thematically-structured academic journals, it would perhaps be somewhat less possible to offer so much space to individual academic publications; often annotations can already be found in other places. In contrast, annals - papers in which the records and reports of a learned field are compiled - are also essential for journals with an academic focus. ${ }^{45}$ In the hard sciences, they often constitute a separate group of journals. 'Reviews ('annals' C. S.) are of immense value to scientists who wish to familiarise themselves with the state of the art in a particular field before committing themselves to a research project'. ${ }^{46}$

\section{Furthering the debate}

Some disciplines have the experiment as the means of furthering scientific progress. Law does not have such a thing, except insofar as it is a true behavioural science. Our knowledge is derived primarily from argument. For us, the debate is the means of scholarly progress. Journal editors who choose an academic focus should view, as their most important task, the need to guarantee the quality of the debate and, as far

42 Ibid, p 27.

43 Posner, Richard A, 'Legal scholarship' (2002) 115 Harvard Law Review 1314. He makes an exception of Kelsen's work.

44 For the law reviews of US law schools that are mainly 'state' schools rather than 'national' schools, however, there is a tension between selection of articles that will be of interest to the regular 'state' readership of the review (which is also the principal support of the law school) and selection of articles that will enhance the national reputation of the review and the law school.

45 It need not be journals per se; international public law has a number of yearbooks containing a successful combination of scientific papers, annals and publication of inaccessible source material about the practice of international law involving states and international organisations.

46 Houghton, op cit, 1975, p 35, see fn 37. 
as possible, to improve it, since such improvement is certainly possible. It was with this in mind that Jan Vranken, a Dutch academic, noted the non reporting of 'the real, underlying considerations and choices [to be] ... characteristic of arguments in civil law'. If such is the case, one might then expect more attention to be paid to this fact in the testing procedures undertaken by editorial boards. And the issue may still be even more basic: does the author investigate the results of others? Lawyers have, by nature, a strong tendency to cite others. And they then primarily have eyes for authors who confirm their own theory. Much more than seeking confirmation for a theory, the researcher should be directed at contrasting observations or analysis, or at conflicting legal decisions. It is noteworthy that lawyers have developed such elegantly elaborated and regulated 'debating models' for our procedural law, while those for academic research are nearly non-existent.

Journal editorial staff must give some consideration to the manner in which they perform their testing duties. Many academic disciplines use external peer review; ${ }^{47}$ legal scholarship does not, apart from a few international exceptions. ${ }^{48}$

With the growing publication pressure at universities, such an extra test - one that therefore extends beyond the usual editorial checks - will probably be unavoidable for most academic journals. And finally, should we not, in accordance with the American custom and the one adopted in many other disciplines, provide every article with a closing and careful conclusion? Good conclusions and/or abstracts are so important because of the likelihood that readers will read the article's conclusion before, or instead of, reading the body of the article.

\section{PhD degree based on articles}

Even those who do not wish to hand themselves entirely over to Popper cannot avoid the fact that scholarship ought to be as 'open' as possible - openness in the manner of producing publications and the choice of method. Academic research on law is mostly individualistic research and, during the research process, there is very little written exchange of ideas. This shortcoming also applies to dissertations. PhD candidates often publish the result of years of research all at once. Besides the dissertation supervisor and perhaps a few confidants, no one has seen the research design, the initial findings or the provisional conclusions ahead of time. Furthermore, PhD candidates only assemble the doctoral committee once the book is finished. It is questionable if, viewed in terms of the interests of an open scholarly debate, such practice is sensible. In the sciences, $\mathrm{PhD}$ candidates already have a substantial number of publications under their name; often the doctoral degree is awarded on the basis of these articles. These earlier publications have then already played a role in the

47 LaFollette thoroughly investigates all sides of the peer review issue, op cit, 1992, p $119 \mathrm{ff}$, see fn 38. In her book, she also pays considerable attention to 'referee misconduct' ('Referees can also be the villains', p 127).

48 There are an increasing number of peer reviewed journals in international law. In the US the 'law and ...' another disciplines are famous exceptions. British journals, too, are making more and more use of external peer review. In some cases this has been influenced by the Research Assessment Exercise (RAE) ${ }^{48}$. While it is still the case that some of the leading journals in the UK are not peer reviewed, this has now become the exception. 
scientific debate. Doctoral degrees based on articles can and must become more popular in legal scholarship.

\section{Vision on internationalisation}

In this era, all academic journals should at least have a vision or opinion on internationalisation. Is a comparative approach in certain legal disciplines a condition for publication? Do periodicals with academic objectives have to impose conditions on their authors requiring them to at least cite publications from certain international journals? This would create 'allied journals' - preferred partners - and would contribute to the internationalisation of legal scholarship. But it is only fair to also mention some objections that could be raised against these proposals, including discouragement of articles on domestic law subjects, citations relating to foreign law by authors who are not knowledgeable about it, and preferred and thus biased citation of an article in the partner journal when an unbiased author would not cite that article.

Double publication in a national journal and subsequently in a foreign journal, and the author receiving a double credit for such publication, appears to me to be quite acceptable as well, although this is generally deemed impermissible in other disciplines. ${ }^{49}$ But since it involves two separate readerships with their own medium, this form of double publication is, to my mind, entirely justifiable.

In a commentary to a draft version of this article, I was made aware that one feature of internationalisation must be kept a close eye on, that is the advantage that Dutch and Flemish scholars often still have insofar as the knowledge of languages is concerned. But the same is true for scholars from many other European countries. Even in the work of international and EC law, it is recognised that English-speaking scholars, on the one hand, and the southern European French speakers, on the other, have divided themselves into language-bound 'citation communities'; the same holds true for German lawyers, though to a lesser degree. It should be generally recognised that the strong point of Dutch, Flemish and other legal professionals is that they are ready and able to gain knowledge from the practices and literature in these three large language areas. They consequently make intellectual connections that would be otherwise neglected. They should guard against the possibility that academic English takes the lead too easily.

Furthermore, academic periodicals must give greater consideration to what is being published in other countries. Abstracts in several languages should be the means used for this purpose. ${ }^{50}$ In this way, the debate would automatically become more international.

\section{Advancing 'science communication'}

Authors wish to be read as much as possible and to have the greatest possible influence ('impact'). In selecting the appropriatejournal, they will also examine the performances

49 See, for biomedical journals for example, the so-called Vancouver Rules: www.icmje.org.

50 The Canadian practice is to have abstracts in French and English of every article. 
of the journal 'on the market'. This market consists not only of colleagues and professional practitioners, but also 'the public at large'. Journals such as Science and Nature therefore have journalists on staff who explain the (incomprehensible) scientific publications to the general public in regular features such as 'news and views'. The Dutch Minister of Education, Culture and Science even regards communication between the various disciplines and the public as an official task of universities and other research institutes. The academic discipline, as an essential component of all cultures including that of the Netherlands, is obliged to provide the community with an account of itself. Not all legal researchers communicate so easily with the public at large.

\section{Ranking of journals}

I expect that, in the short term, a method of ranking legal journals will come into being. This appears unavoidable, even if it has only been used by universities and funding organisations as a tool to measure the quality of a researcher or a research group. ${ }^{51}$ In America, various types of ranking already exist. It is not unlikely that an appropriate next step would involve the allocation of an 'impact factor' to periodicals. And over the longer term, a development in the direction of a citation index for academic legal research is not to be excluded. ${ }^{52}$ However, it is good to remember that academic journals are no 'better' than professional journals. The issue here involves 'focus'.

\section{Accessibility of publications}

In the Netherlands and in most other European countries, it is not possible - as it is in the US with Westlaw, Lexis/Nexis, or HeinOnline - to obtain a complete survey of all the journal publications and search the full text. Such a capacity is essential for all current academic research. Moreover, anyone hearing that scientists in the medical field, for example, automatically receive on their screens weekly the contents of journals of their choice is overcome with envy. All legal scholars and practitioners must be provided with these facilities. ${ }^{53}$ The accessibility of scholarly literature about law

51 Of course it would be unfair to younger scholars if editors were also selecting articles by name and reputation of author. That should be avoided.

52 This is connected to one of the major issues for US (and other) law reviews: should the identity of the author be a factor in the selection of an article for publication? Should it matter that the author has a high academic reputation, or attracts interest/attention, or is on the faculty of a high-ranking law school? Should diversity of authors (as distinct from diversity of article content) be a factor? Some people have argued that law review editors are too influenced by the identity of the authors. There have been proposals for totally 'author-blind' review and selection of articles. I understand that some law journals have implemented this, at least for consideration of articles by external reviewers. On the other side, journal editors want the articles published in the journal to be noticed, read and cited. That is more likely to happen if the author is wellknown. And publishing prominent authors attracts submissions from other authors who are prominent or at high-ranking schools.

53 It is a deficiency of Lexis and Westlaw that they do not reproduce text in pdf format, except for some of the case reports in Westlaw. This is especially a deficiency for journal articles. Therefore, legal academics and others are increasingly using databases with PDF-versions of articles and there is a market for providing material in pdf, which reproduces the publications exactly in a readable form. HeinOnline provides this for legal scholarship. 
is, in most countries, far behind the current availability of case law and legislation. In this regard, there is an important development in the Netherlands that bears mentioning: the DARE (Dutch Academic Repositories) project. In the Netherlands, support from such organisations as the Royal Netherlands Academy of Arts and Sciences (KNAW) has enabled a beginning to be made on the publication on the internet of all (already published) academic articles, including those by legal scholars. More than 200 scientists (among them lawyers) in the Netherlands, with over 41,000 publications, are already accessible for everyone. About $60 \%$ is full text available; the rest has copyright restrictions. ${ }^{54}$ This is a scheme that should ultimately lead to all academic publications becoming freely accessible by means of the internet.

\section{Transparency: independence of the author}

Scholarly research ought to be as independent as possible and transparent. For example, whenever a scientist is commissioned to conduct research, this commissioning partner should not have any influence on the research results. Names of external financiers should always be mentioned in the publication. ${ }^{55}$ Major medical journals, both in Europe and the US, have elaborate rules on this. I would like our journals to formulate and to uphold strong requirements concerning this point. ${ }^{56}$ This is not done consistently by any one of them. Scholarship - just as independent jurisprudence - is one of the most costly achievements of our culture. Huizinga puts it so elegantly in De Gids: 'Actually, modern civilization does not have too many anchors, but one of them is the independent pursuit of knowledge. ${ }^{57}$

\section{Composition of editorial boards}

The editorial staffs of monodisciplinary periodicals are generally also composed of monodisciplinarians. But scholarly progress often takes place where various disciplines overlap. Consequently, it is not out of place to say that the editorial boards of these monodisciplinary journals should include representatives from other disciplines: meta-legal fields, public administration, but also - in the case of, for example, criminal law journals - private law or administrative law. An objection raised against this argument takes the position that every journal should limit itself to its own discipline. However, strangers in our midst constitute a sovereign remedy against group think. In a creeping manner, dominant theories in the field or preferences for certain types of publications or subjects can hamper progress in any given scholarly area. In a fascinating book, Marjorie Garber, an American literary scholar, writes about the relationship between the 'amateur' and the 'professional'. ${ }^{8}$ She believes that we as scholars should tread precisely on each other's terrain and she advocates 'discipline

54 See http://www.keurderwetenschap.nl/en/page/language.view/keur.page.

55 See the aforementioned Dutch Code of Conduct, par. V ('Independence').

56 See the inaugural address of 8 January 2004 by Paul F. van der Heijden, Publiek vertrouwen, (in Dutch), not yet in print, but available at www.uva.nl.

57 Huizinga, Johan, 'Overheid en wetenschap', De Gids, 1925, p 392 (in Dutch). He is particularly concerned with the influence of government on scientific research.

58 Garber, Marjorie, Academic Instincts, 2001, Ewing, New Jersey: Princeton U. 
envy': the passionate desire to say something about another's field. Of course, writes Garber, 'discipline envy' also requires 'disciplined envy'. ${ }^{59}$

Finally, journal editors and reviewers ought to rotate. This is also normal in the sciences, not only done in order to provide opportunities for new people, but to again prevent a form of group think from occurring.

\section{Joint publications}

I expect that the number of co-productions will increase; not only involving two authors, but more. As research on law comes to require more teamwork (in other disciplines, one speaks of research groups), joint authorship will become inevitable. Legal scholars are still quite reticent in this respect, but experiments with such programmes as the so-called research masters will cause supervisors to jointly publish with their students. I would venture to say that the quality of publications will improve as a result. ${ }^{60}$ For the PhD supervisors, joint publication is a stimulus to devote more time to the research of their doctoral candidates. It also promotes the involvement of colleagues in each other's work. In law, we need not fear such aberrations as those that occur in physics or biology, where articles with more than 100 authors are not the exception. ${ }^{61}$ But it would be good if editorial boards gave some thought to co-productions and the limits to be imposed on them.

\section{CONCLUSION}

In 1942, the American sociologist of science, Robert Merton, suggested as one of the norms of academic science that universities ought to be places of 'organised scepticism'. ${ }^{62}$ Academic journals should, in turn, contribute to this mission, since the quality of an academic discipline largely depends on the quality of its publication culture. Informed by the American experiences including the dominant law reviews there, and by contrast an international medical journal, I tried to obtain a better view of the publication culture involving legal scholarship in many European countries and the possibilities of improving it. We should think more about the future of our legal journals - the first scholarly journal of all was founded by a lawyer. ${ }^{63}$ Changes should be considered at many points with, of course, an eye for the peculiarities of the legal discipline and for the mistakes made in other academic fields. The responsibility for change lies with editors, but also with authors, universities and research institutes.

59 Ibid, p 61.

60 There are many factors involved in this; see, for example, Hartley, James, 'Single authors are not alone: colleagues often help' (January 2003) Journal of Scholarly Publishing, vol 34, no 2, whose study of a few psychology journals leads him to conclude that 'single authors' more often enlist assistance from colleagues than 'double authors' do.

61 See, for example, articles such as 'Initial sequencing and comparative analysis of the mouse genome' (December 2002) Nature 420, pp 520-62, which lists 221 'authors'.

62 Merton, RK, The Normative Structure of Science, in The Sociology of Science: Theoretical and Empirical Investigations, 1942, Chicago: Chicago UP, pp 267 ff.

63 The history of the scholarly journal began on 5 January 1665 with the publication of the Journal des Scavans, founded by Denis de Sallo. See Houghton, Bernard, op cit, p 13, see fn 37. 
Furthermore, the poor access to legal literature must be quickly remedied. This is a task for publishers, but also for national organisations for scientific research, or academies of science.

Rodell, whose famous rant led me to write this article, vowed never again to write an article for a law review. At the request of the journal in which he made this vow, he once returned to this subject. ${ }^{64}$ His annoyance was unmodified: 'Ah, [legal] scholarship; ah, nuts. ${ }^{65}$

64 Rodell, Fred, ‘Goodbye to law reviews - revisited, (1962) 48 Va. L. Rev. 279.

$65 \mathrm{Ibid}, 1962, \mathrm{p} 290$. I have added the word 'legal' to this quote to make Rodell's meaning more apparent. 